\title{
ANALYSIS OF AN ALTERED SIMPLE SILICATE GLASS USING DIFFERENT MINERAL AND GLASS STANDARDS
}

\author{
James J. Mazer and John K. Bates \\ Argonne National Laboratory \\ Chemical Technology Division \\ 9700 South Cass Avenue \\ Argonne, IL 60439-4837 \\ Submitted to \\ SCANNING 89/EM West \\ Long Beach, California \\ Apri $5-7,1989$
}

\section{DISCLAIMER}

This report was prepared as an account of work sponsored by an agency of the United States Government. Neither the United States Government nor any agency thereof, nor any of their employees, makes any warranty, express or implied, or assumes any legal liability or responsibility for the accuracy, completeness, or usefulness of any information, apparatus, product, or process disclosed, or represents that its use would not infringe privately owned rights. Reference herein to any specific commercial product, process, or service by trade name, trademark, manufacturer, or otherwise does not necessarily constitute or imply its endorsement, recommendation, or favoring by the United States Government or saly agency thereof. The views and opinions of authors expressed herein do not necessarily state or reflect those of the United States Government or any agency thereof. 


\section{ANALYSIS OF AN ALTERED SIMPLE SILICATE GLASS USING DIFFERENT MINERAL AND GLASS STANDARDS}

James J. Mazer and John K. Bates

Argonne National Laboratory, 9700 South Cass Avenue, Argonne, IL 60439

Quantitative analyses of alteration products formed during the aqueous corrosion of glass were performed using four different sets of standards: relevant mineral standards, an NBS glass standard, and the unreacted center of the reacted glass. A simple silicate glass (containing $\mathrm{Na}, \mathrm{Mg}, \mathrm{Al}, \mathrm{Si}$, and $\mathrm{Ca}$ ) was reacted in water vapor at $200^{\circ} \mathrm{C}$ for 14 days. Up to eight alteration phases, including a Mg-rich smectite clay and a zeolite intermediate in composition between ca-harmotome and phillipsite, formed on the glass surface. A set of EDS spectra of the bulk glass, the clay, and the zeolite were collected from a polished cross-section of the reacted sample.

The sum of the elemental weight percents varied by as much as $48 \%$ using the different standards. These differences are due to poor electrical conductivity through the clay layer. When the analyses were normalized to $100 \%$, the differences between analyses using the standards were small (less than $10 \mathrm{wt} \%$ for individual cations and $<5$ total wt $\%)$. Normalization is inappropriate in the analysis of hydrated alteration phases, which contain a significant amount of water. The inability of the EDS system to detect water requires that absolute analyses be used in order to estimate the water content of the alteration phases. The bulk glass standard analyses were best suited for this purpose. In addition, use of the bulk glass as a standard is preferable in our application because spectra of the altered layer and bulk glass can be acquired from the same specimen. Analytical errors that may occur due to poor conductivity through the reacted layer, drifting probe currents, or varying thickness of the carbon coating are also reduced. 


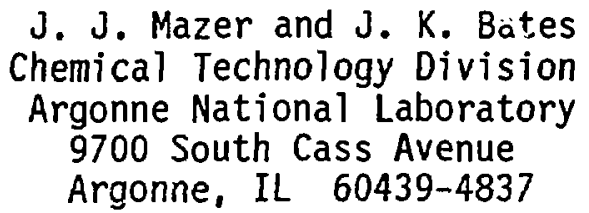

\section{INTRODUCTION}

The interactions that occur between silicate glasses and water have been studied by researchers in many disciplines, including chemists, geologists, and material scientists. These reactions are of particular interest to the nuclear waste industry, which is considering borosilicate glass as a waste form to encapsulate high-level radioactive wastes for eventual disposal in a geologic repository. Water contacting the glass is thought to be the most likely avenue of release for radionuclides from the repository. It is known that water-glass reactions are dependent on the solution $\mathrm{pH}$, reaction temperature, giass surface area to solution volume ratio, and the compositions of the glass and solution. Glass-water reactions generally result in an alteration layer and secondary mineral phases forming on the glass surface as a result of water-cation exchange. For a complete understanding of glass/water reaction, identification of these secondary phases is necessary.

Water is an important component of the alteration products formed on these samples. SEM/EDS analyses of unknown samples using external standards is unable to account for $\mathrm{H}_{2} \mathrm{O}$ present in the reacted layer. By using the unreacted glass interior of a reacted sample as an analytical standard, an estimate of the $\mathrm{H}_{2} \mathrm{O}$ content of the reaction products can be 
made by assuming that the difference from $100 \%$ in the analyses is due to $\mathrm{H}_{2} \mathrm{C}$ (the analyzed total weight percent of a reacted layer was always less than 10c\%). Previous studies of alteration products formed on hydrated glasses have not accounted for $\mathrm{H}_{2} \mathrm{O}$ in the analyses, but simply normalized the analyses to $100 \%$ total weight (cf. [MURAKAMI, BERGER, AILIN-PYZIK]).

An alternate technique which uses the unreacted bulk glass as an analytical standard is described. The results of analyses using this technique are compared to analytical results using mineral standards and an NBS $\mathrm{g}$ ? ass standard. The differences between the results using the different standards is discussed.

\section{EXPERIMENTAL}

A simple glass was synthesized from oxides and carbonates of $\mathrm{Na}, \mathrm{Mg}$, $\mathrm{Al}$, Si, and $\mathrm{Ca}$. Glass monoliths, discs approximately $1 \mathrm{~cm}$ diameter, were reacted in a $100 \%$ relative humidity atmosphere for 28 days at $200^{\circ} \mathrm{C}$. Polished cross-sections ( 0.3 micron firial polish) were carbon coated (approximately $200 \AA$ ) prior to analysis. Examination of the cross-section samples revealed that an alteration assemblage had formed, that varied from 15-30 $\mu \mathrm{m}$ in total thickness. This heterogeneous assemblage included up to eight distinct phases, shown in Figure 1. The alteration products include calcium- and sodium-bearing aluminosilicates, a calcium phase (probably calcium carbonate), and two different calcium silicate phases. 


\section{ANALYTICAL RESULTS}

Spectra were collected on an ISI SS40 SEM with a Princeton Gamma-Tech (PGT) energy dispersive $x$-ray spectrometer. Quantitative analyses were performed using PGT System IV software. A $10 \mathrm{keV}$ beam was used with a Faraday cup probe current of 1.0 nanoamp for collection times of 100 seconds. Spectra were collected from broad areas (20 to $100 \mu \mathrm{m}^{2}$ ) to minimize possible $\mathrm{Na}$ diffusion away from the analyzed area. These spectra were chen corrected using ZAF procedures to derive elemental concentrations. The oxygen concentration was calculated by stoichiometry.

For elements present in concentrations greater than $10 \%$, the relative accuracy of the system is 1 to $5 \%$. Eloments present in quantities between 1 and $10 \%$ have relative accuracies of 5 to $50 \%$. In the 0.1 to $1 \%$ range relative accuracies of 50 to $100 \%$ are found [BARBI].

Analytical standards included a basalt glass, USNM 111240/52, referred to as STD $A$, and mineral standards, including Amelia Albite \#4 (Na, Al, and $\mathrm{Si})$, synthetic spinel $(\mathrm{Mg})$, and wollastonite (Ca), referred to collectively as STD B. In addition to mineral and glass standards, the unreacted glass from the center of the cross-sectioned reacted samples was treated as a standard, STD C. An unreacted simple glass sample, identical in composition to STD $C$, was also prepared, referred to as STD D. The composition of each standard is presented in Table 1. Several spectra collected from each standard set (i.e., the unr the glass, mineral standards, or the reference glass) were averaged to create each analytical standard spectrum. Several spectra of the unreacted glass in the center of a reacted sample were analyzed using these four different standards. The results are presented in Table 2 in terms of tocal weight percent and atomic percent. 
Atomic percentage results allow comparisons to be made between analyses of areas where $x$-rays may not have been as efficiently generated due to effects such as uneven polishing of the reacted layer or uneven carbon coating. Variations in the constituent spectra from STDs $A$ and $B$ were within the analytical error of measurement and suggest that the standards are homogeneous. STDs $C$ and $D$ showed variations in the amounts of $N a$ which may reflect inhomogeneities in the glass or Na migration. The variation of all other elements were within the analytical error.

When external standards (STDs $A$ and B) were used to quantitatively analyze the unreacted glass in the center of a reacted sample, the measured total weight percents were approximately $120 \%$ of the known values, although the atomic weight percents were in good agreement. When the unreacted bulk glass (STD D) was used to analyze the unreacted interior of the reacted sample, the measured total weight percents were as high as $140 \%$ of the kriown values. As with the other external standards, when these values were normalized to $100 \%$, the values were in good agreement with the known values.

The disparity in the analyses generated using STD D suggests that the presence of the alteration phases on the glass surface affect the efficiency of $x$-ray production in the bulk glass. In order to investigate this hypothesis, a different analytical configuration of the samples were devised and additional standard spectra collected. Silver paint was used to provide a conductive pathway which circumvented the reaction layer by forming a ring arouni a portion of the unreacted glass and extending to the brass sample holder, as depicted in Figure 2. In this way, any effect the reacted layer might have on the analysis would be eliminated. 
A second series of analyses of tine unreacted glass center from the center of a reacted sample in the alternate configuration were performed using standard spectra also collected in the alternate configuration. These results are presented in Table 3. Analyses made from spectra collected in this configuration, referred to as STO $A^{\prime}$, STD $C^{\prime}$, and STD $D^{\prime}$, are within the analytical errors of the known values of the simple glass, and do not require renormalization, as was necessary in the absence of a surrounding silver ring. It appears that the softer, friable alteration layer, in contact with relatively hard glass and mounting resin was not evenly polished and fractured and cracked in several instances. When the mount was subsequently carbon coated this surface was incompletely covered, resulting in poor electrical conductivity. Apparently, the net effect is a slight charging on the sample that deflects the electron beam from the target. This results in fewer electrons interacting with the samples which generates fewer $x$-rays than would be generated from a non-charging sample. When the bulk glass from the interior of a reacted sample is used as a standard, the charging effect is present when both the standard and layer analyses are collected and so all spectra are acquired under similar conditions. Analyses, therefore, do not require normalization to determine absolute weight percents.

It has been shown that the hydrothermal alteration of glass is primarily a function of the initial glass composition, the reaction temperature, the solution chemistry, and the duration of reaction (for a recent review see [ADAMS]). Each of these factors has an effect on the composition, crystallinity, and amount of each alteration phase. It is, therefore, impractical to analytically describe the charging effect and 
avoid the need for normalizing analyses. While it would be possible to prepare samples for quantitative analyses by applying silver paint pathways to prevent sample charging, we have found that it is more advantageous to use the unreacted bulk as an analytical standard because this allows examination of the entire sample. This technique allows the water content of alteration phases to be estimated, as discussed earlier, and produces analyses which are similar to those obtained using conventional standards.

\section{v. CONCLUSIONS}

The generation of $x$-ray spectra from a hydrated bulk glass is significantly affected by the presence of the reaction layer on the glass surface. Quantitative analyses using external standards are stoichiometrically correct, but significantly different, up to $50 \%$, in actual values. Analyses of phases within the reacted layer using the unreacted glass in the center of the sample as the analytical standard result in analytical values which do not require normalization and are similar to those obtained using conventional standards. This is preferable in our applications because this allows an estimate of the water content of the alteration phases to be made.

\section{ACKNOWLEDGMENTS}

Work supported by the U.S. Department of Energy, Office of Geologic Repositories, Yucca Mountain Project, under Contract Number W-31-109-38. 


\section{VII, REFERENCES}

ADAMS

P. B. Adams, "Glass Corrosion a Record of the Past? A Predictor of the Future"," J. Non-Cryst. Solids 67, 193-205 (1984).

AILIN-PYZIK

I. B. Ailin-Pyzik and S. E. Sommer, "Microscale Chemical Effects of Low Temperature Alteration of DSDP Basaltic Glasses," J. Geophys. Res. 86 (B10), 9503-9510 (1981).

BARBI

N. C. Barbi, "Electron Probe Microanalysis Using Energy Dispersive X-Ray Spectroscopy," Princeton Gamma-Tech Manuzi, Princeton Gamma-Tech, Princeton, NJ (1977).

\section{BERGER}

G. Berger, J. Schott, and M. Loubet, "Fundamental Processes Controlling the First Stage of Alteration of a Basalt Glass by Seawater: An Experimental Study between $200^{\circ}$ and $320^{\circ} \mathrm{C}$, " Earth and Planet. Sci. Lett. 84, 431-445 (1987).

JAROSEWICH

E. Jarosewich, J. A. Nelen, and J. A. Norberg, "Reference Samples for Electron Microprobe Analysis, "Geostandards Newsletter 4 (1), 43-47 (1980).

\section{MURAKAMI}

T. Murakami, R. C. Ewing, and B. C. Bunker, "Analytical Electron Microscopy of Leached Layers on Synthetic Basalt Glass," Mat. Res. Soc. Symp. Proc. 112, 737-750 (1988). 
Table 1. Compositions of Minerals and Glass Standards Used for Quantitative Analysis of Analog Basalt Vapor Hydrated for 28 Days at $200^{\circ} \mathrm{C}$

\begin{tabular}{|c|c|c|c|c|c|}
\hline \multirow[b]{3}{*}{ Element } & \multicolumn{5}{|c|}{ Wt $\%$} \\
\hline & \multirow{2}{*}{$\frac{\text { STD A }}{\text { USNM }}$} & \multicolumn{3}{|c|}{ STD B } & \multirow{2}{*}{$\begin{array}{l}\text { STD C + } \\
\text { STD D } \\
\text { Simple } \\
\text { Silicate } \\
\text { Glass }\end{array}$} \\
\hline & & $\begin{array}{l}\text { Amelia } \\
\text { Albite } \\
(\# 4)\end{array}$ & $\begin{array}{l}\text { Synthetic } \\
\text { Spinel } \\
\left(\mathrm{MgO} \bullet \mathrm{Al}_{2} \mathrm{O}_{3}\right)\end{array}$ & $\begin{array}{l}\text { Wolla- } \\
\text { stonite \#2 } \\
\left(\mathrm{CaSiO}_{3}\right)\end{array}$ & \\
\hline $\mathrm{Na}$ & 1.94 & 8.50 & - & - & 2.15 \\
\hline $\mathrm{Mg}$ & 4.05 & - & 17.09 & - & 8.08 \\
\hline$A I$ & 7.44 & 10.46 & 37.93 & - & 9.05 \\
\hline Si & 23.75 & 31.85 & - & 24.18 & 25.47 \\
\hline K & 0.16 & 0.19 & - & - & - \\
\hline $\mathrm{Ca}$ & 7.95 & 0.27 & - & 34.50 & 8.64 \\
\hline $\mathrm{Ti}$ & 11.11 & - & - & - & - \\
\hline$M n$ & 0.14 & - & - & - & - \\
\hline $\mathrm{Fe}$ & 9.20 & 0.007 & - & - & - \\
\hline $0^{*}$ & 44.03 & 48.70 & 44.98 & 41.32 & 46.61 \\
\hline$P$ & 0.09 & - & - & - & - \\
\hline TOTAL & 99.86 & 99.98 & 100.00 & 99.99 & 100.00 \\
\hline
\end{tabular}

*By stoichiometry.

Set A was obtained from the Smithsonian Institute [JAROSEWICH]. Set B was obtained from the C. M. Taylor Corporation. Sets $C$ and $D$ are the "as mixed" compositions of the glass used in hydration experiments. 
Table 2. Quantitztive Analyses of Bulk Glass in a Reacted Sample Using Four Analytical Standards

\begin{tabular}{|c|c|c|c|c|c|}
\hline & \multicolumn{5}{|c|}{ Weight Percent } \\
\hline & $\begin{array}{c}\text { Simple Silicate } \\
\text { Glass } \\
\text { Composition } \\
\text { As Mixed }\end{array}$ & STD A & STD B & STD $\mathrm{C}$ & STD D \\
\hline $\begin{array}{l}\mathrm{Na} \\
\mathrm{Mg} \\
\mathrm{Al} \\
\mathrm{Si} \\
\mathrm{Ca} \\
0\end{array}$ & $\begin{array}{r}2.15 \\
8.08 \\
9.05 \\
25.47 \\
8.64 \\
46.61\end{array}$ & $\begin{array}{r}2.41 \pm 0.35 \\
9.93 \pm 0.14 \\
10.50 \pm 0.14 \\
30.60 \pm 0.27 \\
10.54 \pm 0.15 \\
55.78 \pm 0.53\end{array}$ & $\begin{array}{r}2.07 \pm 0.30 \\
9.40 \pm 0.14 \\
10.67 \pm 0.14 \\
31.08 \pm 0.28 \\
10.46 \pm 0.14 \\
56.00 \pm 0.53\end{array}$ & $\begin{aligned} 2.15 & \pm 0.32 \\
8.09 & \pm 0.12 \\
9.06 & \pm 0.12 \\
25.48 & \pm 0.23 \\
8.64 & \pm 0.12 \\
46.58 & \pm 0.45\end{aligned}$ & $\begin{aligned} 4.41 & \pm 0.64 \\
10.49 & \pm 0.16 \\
13.11 & \pm 0.18 \\
5.98 & \pm 0.33 \\
12.94 & \pm 0.18 \\
66.25 & \pm 0.71\end{aligned}$ \\
\hline \multirow[t]{3}{*}{ TOTAL } & 100.00 & $119.75 \pm 1.24$ & $119.75 \pm 1.21$ & $99.97 \pm 1.06$ & $143.16 \pm 1.77$ \\
\hline & \multicolumn{5}{|c|}{ Atomic Percent } \\
\hline & $\begin{array}{c}\text { Simple Silicate } \\
\text { Glass } \\
\text { Composition } \\
\text { As Mixed }\end{array}$ & STD A & STD B & STD C & STD D \\
\hline $\begin{array}{l}\mathrm{Na} \\
\mathrm{Mg} \\
\mathrm{Al} \\
\mathrm{Si} \\
\mathrm{Ca} \\
0\end{array}$ & $\begin{array}{r}1.95 \\
6.93 \\
7.00 \\
18.91 \\
4.50 \\
60.72\end{array}$ & $\begin{aligned} 1.82 & \pm 0.26 \\
7.12 & \pm 0.11 \\
6.81 & \pm 0.08 \\
18.97 & \pm 0.09 \\
4.58 & \pm 0.05 \\
60.73 & \pm 0.11\end{aligned}$ & $\begin{aligned} 1.57 & \pm 0.22 \\
6.74 & \pm 0.11 \\
6.98 & \pm 0.04 \\
19.27 & \pm 0.08 \\
4.58 & \pm 0.05 \\
60.96 & \pm 0.10\end{aligned}$ & $\begin{aligned} 1.79 & \pm 0.38 \\
6.93 & \pm 0.10 \\
7.06 & \pm 0.08 \\
18.92 & \pm 0.10 \\
4.50 & \pm 0.05 \\
60.72 & \pm 0.11\end{aligned}$ & $\begin{aligned} 2.79 & \pm 0.38 \\
6.29 & \pm 0.10 \\
7.09 & \pm 0.04 \\
18.69 & \pm 0.13 \\
4.71 & \pm 0.06 \\
60.42 & \pm 0.16\end{aligned}$ \\
\hline TOTAL & 100.00 & 100.03 & 100.10 & 99.92 & 99.99 \\
\hline
\end{tabular}

Sets $C$ and $D$ differed in that set $C$ was experimentally hydrated and had in alteration covering the surface. Spectra were collected from the unreacted interior of the sample. Sets $A$ and $B$ are external glass and mineral standards (see text). 
Table 3. Quantitative Analyses of Bulk Glass in a Reacted Sample with Ag Collar

\begin{tabular}{|c|c|c|c|c|}
\hline & $\begin{array}{c}\text { Simple Silicate } \\
\text { Glass } \\
\text { Composition } \\
\text { As Mixed }\end{array}$ & $\begin{array}{c}\text { STD } A^{\prime} \\
(w / A g C o l l a r)\end{array}$ & $\begin{array}{c}\text { STD C' } \\
\text { (w/Ag Collar) }\end{array}$ & $\begin{array}{c}\text { STD D' } \\
(w / A g ~ C o l l a r)\end{array}$ \\
\hline \multicolumn{5}{|c|}{ Weight Percent } \\
\hline $\begin{array}{l}\mathrm{Na} \\
\mathrm{Mg} \\
\mathrm{Al} \\
\mathrm{Si} \\
\mathrm{Ca} \\
0\end{array}$ & $\begin{array}{r}2.15 \\
8.08 \\
9.05 \\
25.47 \\
8.64 \\
46.61\end{array}$ & $\begin{array}{r}2.00 \\
7.83 \\
8.49 \\
25.48 \\
9.66 \\
46.28\end{array}$ & $\begin{array}{r}2.13 \\
8.08 \\
9.05 \\
25.47 \\
8.64 \\
46.57\end{array}$ & $\begin{array}{r}2.22 \\
7.81 \\
8.41 \\
26.66 \\
10.73 \\
48.01\end{array}$ \\
\hline TOTAL & 100.00 & 99.74 & 99.94 & 103.84 \\
\hline \multicolumn{5}{|c|}{ Atomic Percent } \\
\hline $\begin{array}{l}\mathrm{Na} \\
\mathrm{Mg} \\
\mathrm{Al} \\
\mathrm{Si} \\
\mathrm{Ca} \\
0\end{array}$ & $\begin{array}{r}1.95 \\
6.93 \\
7.00 \\
18.91 \\
4.50 \\
60.72\end{array}$ & $\begin{array}{r}1.82 \\
6.76 \\
6.61 \\
19.04 \\
5.06 \\
60.72\end{array}$ & $\begin{array}{r}1.93 \\
6.93 \\
7.00 \\
18.92 \\
4.50 \\
60.72\end{array}$ & $\begin{array}{r}1.95 \\
6.49 \\
6.31 \\
19.18 \\
5.42 \\
60.65\end{array}$ \\
\hline TOTAL & 100.00 & 100.00 & 100.00 & 100.00 \\
\hline
\end{tabular}




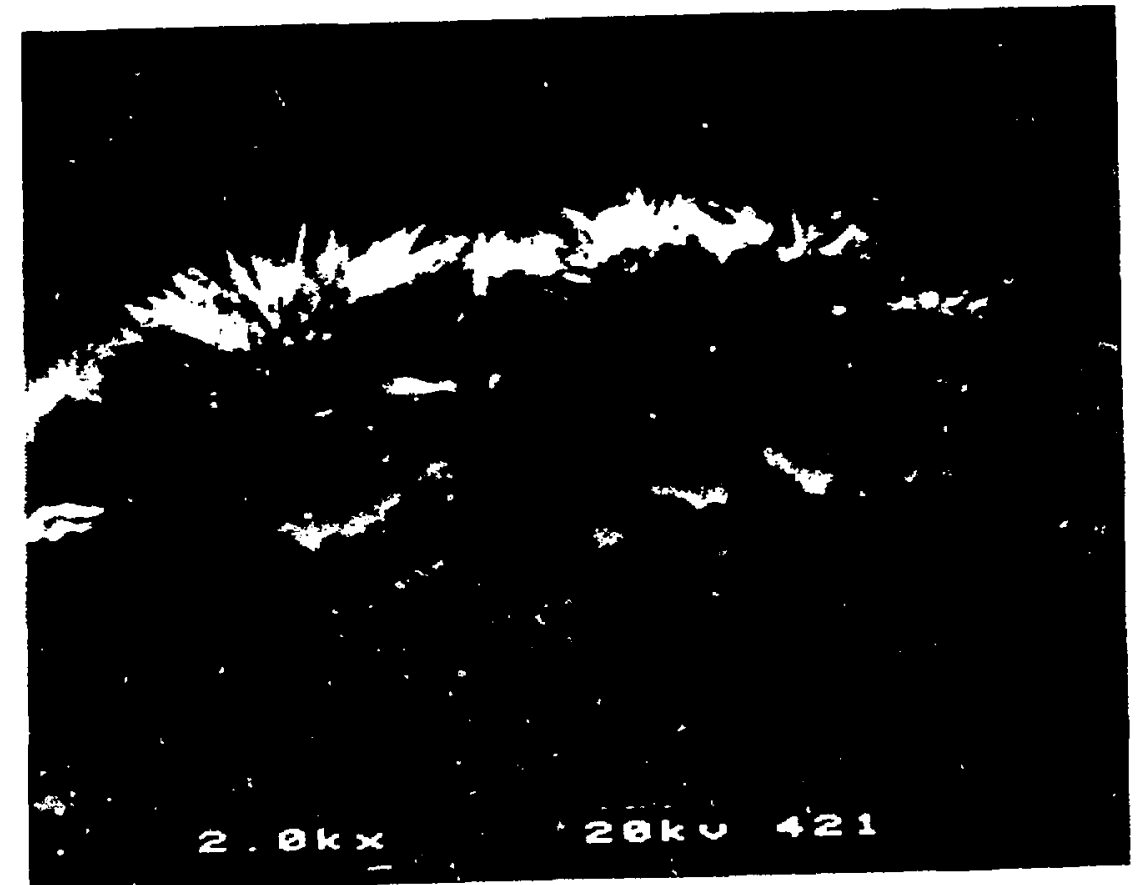

Figure 1. SEM Photomicrograph of the Alteration Products Formed on Vapor Phase Hydrated Glass in Cross-Section (Bar $=1 \mu \mathrm{m})$.

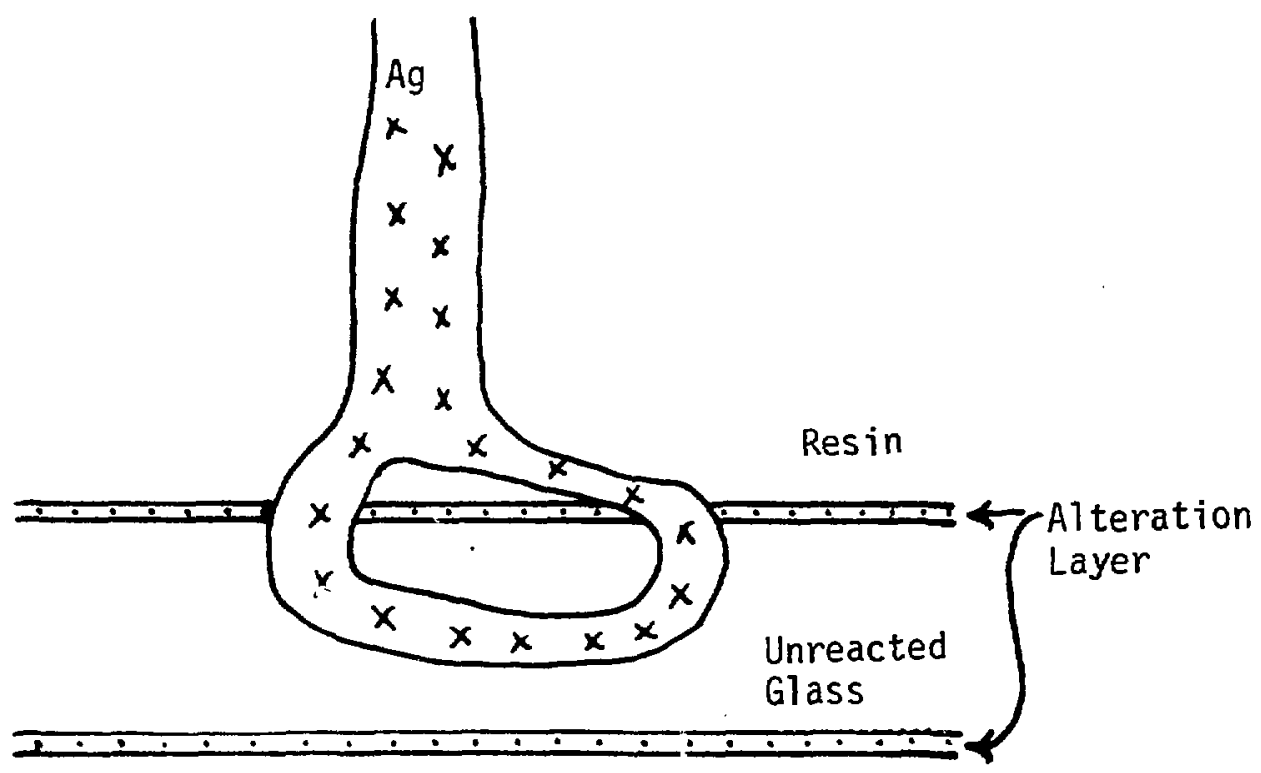

Figure 2. Schematic Drawing of the Alternate Analytical Configuration Used to Assess the Effect of the Alteration Layer on X-Ray Generation from the Unreacted Glass 